\title{
An Integrated Hybrid MCDM Approach for Vendor Selection Problem (Case Study: Iran Khodro)
}

\author{
Massoud Kassaee \\ Assistant Prof., Faculty of Management and Accounting, Shahid Beheshti University, G.C., \\ Tehran, Iran \\ E-mail: M-kassaee@sbu.ac.ir
}

Mojtaba Farrokh (Corresponding author)

Student of master, Faculty of Management and Accounting, Shahid Beheshti University, G.C., Tehran, Iran

Tel: 98-919-692-2470Ｅ-mail: M.farrokh@mail.sbu.ac.ir

Hassan Hosseini Nia

Student of master, Faculty of Management and Accounting, Allameh Tabatabai University, Tehran, Iran

E-mail: h.hoseininiyaa@gmail.com

Received: March 24, 2013 Accepted: April 20, 2013 Published: May 2, 2013

doi: 10.5296/ bmh.v1i1.3623 URL: http://dx.doi.org/10.5296/ bmh.v1i1.3623

\begin{abstract}
Vendor selection is an important issue in most company based on many criteria that includes ambiguous or uncertain data. Therefore in the study, it is essential that fuzzy approach is employed for coping with the uncertainty and achieving more accurate results. In other hand, the relationships between criteria and sub-criteria are complex; for encompassing the complexity, most conventional decision models cannot help us explain the interrelationships among the criteria. In this paper, a hybrid multi-criteria decision making (MCDM) technique is proposed to determine the structural relationships and the interrelationships among all the evaluation's dimensions based the Analytic Network Process (ANP) method determining appropriate weightings to each sub-criterion. Then alternatives priority should be determined which can aid the decision making. For the purpose, The TOPSIS (technique for order
\end{abstract}




\section{Macrothink}

Business and Management Horizons

ISSN 2326-0297

2013, Vol. 1, No. 1

performance by similarity to idea solution) is used to rank all competing alternatives in terms of their overall performances. In MCDM studies and research, applying TOPSIS in ranking alternatives has recently been customary because of its advantages. In the end, a case study of an Iranian company, in automotive industry, is demonstrated to illustrate the proposed model can improve solving of vendor selection problem.

Keywords: Vendor selection problem, Interdependence, Trade-offs, FANP, Fuzzy TOPSIS 


\section{Introduction}

In manufacturing companies, role of raw materials and parts purchasing and outsourcing management is very important and play a vital role on their success and competitiveness and without it companies cannot survive and continue their activities. Given that automotive industry, raw material and component parts purchased from outside vendors consist of considerable portion of the expenses, those must be bought from vendors providing products with reasonable prices and favorable quality in the right place and the time. For most automotive companies, these costs exceed 50 percent of sales (Wadhwa and Ravindran, 2007). In other hand, Weaknesses in the procurement of the materials and goods can cause unemployment of other assets and increasing costs and ultimately reduce profitability and even losses. Thus, almost in all companies, the purchase from outside is considered as a critical responsibility.

One of the most critical tasks in purchasing management is vendor selection, one of the most important functions in the professional management of companies, including a strategic decision for companies' survival (Shyur and Shih, 2006). Moreover, for better handling the outsourcing task, vendor selection is one of the most main activities for many companies. Selection of the incorrect vendor could upset the company's financial and operational condition, while the selection of an appropriate vendor may significantly reduce the purchasing cost and improve competitiveness.

In order to better solve the above-mentioned problems, this paper proposes a hybrid novel MCDM technique that can provide a decision making with better quality. Because data related the criteria of vendor selection issues are ambiguous and uncertain, the fuzzy approach is employed for coping with the uncertainty and attaining more accurate results. To obtain the sub-criteria weightings, ANP method is employed which are able to overcome the problem of interdependence and feedback amongst criteria. Then alternatives priority should be determined which can assist the decision making. For the purpose, The TOPSIS is used to rank all competing alternatives in terms of their overall performances. The TOPSIS is suitable and widely applied as technique for solving MCDM problems based on the concept that the optimal alternative should have the shortest distance from the positive idea solution and the farthest distance from the negative idea solution (Hwang and Yoon, 1981).

In earlier studies, Multi-criteria decision making (MCDM) models have been widely utilized for the vendor selection issue. Ghodsypour and O'Brien (1998) used an integrated AHP and LP approach for the vendor selection and argued that AHP is more precise than other ranking methods. Narasimhan (1983) used the AHP for solving the vendor selection issues. Tam and Tummala (2001) applied an AHP-based model to a real case and indicate that it can improve the group decision making in vendor selection problem.

In spite of the AHP considerable application, it has been recognized that always is not suitable for solving the case that involves intertwined evaluation criteria because each individual criterion may completely be depended to other ones complicating evaluation model. In other word, when AHP should be used in the decision-making that exist a unilateral hierarchical relationship among decision levels (Wu and Lee, 2007). However, Carney and 
Wallnau (1998) argued that the evaluation criteria for alternatives in complex environments are not always independent of each other, but often are dependent to each other.

For coping with the independent, a considerable number of studies have developed decision models based on the MCDM approach. Among the methods, the ANP has been widely considered as an appropriate decision making method. A vendor selection issue usually involves more than one criterion opposing with each other. Lin et al. (2010) employed the ANP method for solving vendor selection problem for a semiconductor company in Taiwan. For coping with the complex and interactive relation among attributes, they also used interpretive structural modeling (ISM) to determine the structural relationships and the interrelationships amongst all the evaluation's dimensions.

In real world, purchasing decision-making includes factors and criteria that their available information in a MCDM process is usually vague and imprecise. Zadeh in 1965 first proposed fuzzy set theory which provided a framework for solving problems in fuzzy environments. Fuzzy set theory is useful when the purchase situation is full of uncertainty and imprecision due to the human judgments making the decision very complex and unstructured.

Some researchers applied fuzzy set theory to curb the vendor selection issue considering uncertainty. De Boer et al. (2001) by providing a comprehensive review of the supplier selection's literature proposed the fuzzy set theory as a way for improving the vendor selection process. In addition, to find the supplier with the best overall performance rating among suppliers, Erol et al. (2003) discussed the advantages of fuzzy set theory in supplier selection issues. Also recently Kumar et al. (2004) have applied a fuzzy goal programming approach for solving the vendor selection problem in supply chain providing a decision method for handle the vagueness and imprecision objectives. Ding and Liang (2005) for selecting a suitable partner for strategic alliance applied fuzzy set theory to solving a complex and multi-criteria problem in an MCDM environment. Yang et al. (2008) used fuzzy AHP and employed the ISM method to clarify the interrelationships of intertwined sub-criteria in the complex structural hierarchy in a vendor selection problem. Faez et al. (2009) applied an integrated model based on the case-based reasoning (CBR) method in a fuzzy environment and mathematical programming for a single item vendor selection issue.

According to the characteristics of the problem and the techniques, we will establish a three-phase hybrid model for vendor evaluation including FANP and fuzzy TOPSIS that can purify adequate criteria and diminish the risk of selecting non-optimal solutions. In first phase, criteria and initial candidate vendors are determined by brainstorming method and also the network relationships among criteria are illustrated as it is essential for achieving the valid results. In the second phase, ANP is used to obtain the relative weights of sub-criteria. Because the criteria are usually interdependent on each other in the vendor selection issue, traditional approaches cannot be applied appropriately. Therefore in the study, the fuzzy analytic network process (ANP) will be applied for obtaining a set of proper weights of the sub-criteria. In the end, given that the performance represented by each alternative, the mission of the fuzzy TOPSIS is to prioritize rival vendors in term of their overall 
performance in respect to multiple attribute (criteria). In vender selection issues, because the effect of each attribute is not always unilateral and must be considered as a trade-off in term of other attributes, the TOPSIS model seem to be an appropriate method as it can include express interactions and trade-offs among attributes. By combining the above two techniques, we can provide a suitable way for properly selecting vendor in a fuzzy environment. This paper also conducted an empirical case study as an illustration to demonstrate how an Iranian company can implement this technique.

\section{Explanation of Methods}

\subsection{Fuzzy Sets}

Fuzzy theory first introduced by Lotfi Zadeh (1965) explaining uncertainty in events and systems where uncertainty arises due to vagueness. Given that data on the phenomenon stated by different experts is ambiguous and vague, applying linguistic term set are necessary to cope with the situations. A linguistic variable is one whose values are linguistic terms, i.e. sentences is to easily express the imprecision qualitative of an experts assessments (Zadeh, 1975). Each linguistic value can be represented by a fuzzy number which can be assigned to a membership function. Among fuzzy numbers, triangular fuzzy numbers have been identified as useful means of quantifying the uncertainty in decision making because of their intuitive appeal and efficiency in computation (Karsak and Tolga, 2001). A positive triangular fuzzy number $\tilde{A}$ can be denoted as $\tilde{A}=\left(a_{1}, a_{2}, a_{3}\right)$ where $\left(a_{1} \geq a_{2} \geq a_{3}\right), a>0$, and if $a_{1}=a_{2}=a_{3}$, " $A$ " cannot be called a fuzzy number anymore. The membership function $\mu \tilde{A}(x)$ quantifies the grade of membership of the element $x$ to the fuzzy set $\tilde{A}$ defined as follows:

$$
\mu \tilde{A}(x)=\left\{\begin{array}{lr}
\left(x-a_{1}\right) /\left(a_{2}-a_{1}\right), & a_{1} \leq x \leq a_{2}, \\
\left(x-a_{2}\right) /\left(a_{2}-a_{1}\right) & a_{2} \leq x \leq a_{3}, \\
0 & \text { otherwise, }
\end{array}\right.
$$

A larger $\mu \tilde{A}(x)$ means a stronger degree of belongingness for $\mathrm{x}$ in $\mathrm{X}$. To better interpret the fuzzy numbers, an important concept regarding the applications of fuzzy numbers is the defuzzification act transforming a fuzzy number into a crisp value (Yager, 1981):

$$
\bar{c}(\tilde{A})=\frac{\int_{a}^{d} x \mu \tilde{A}(x) d x}{\int_{a}^{d} \mu \tilde{A}(x) d x},
$$

Using the centroid defuzzification method: 


$$
\bar{c}(\tilde{A})=\frac{1}{3}\left[a_{1}+a_{2}+a_{3}\right],
$$

In our approach, the linguistic values relying on the scale of 5 points are brought in Table 1.

Table 1. Comparison scale

\begin{tabular}{|l|l|l|l|}
\hline $\begin{array}{l}\text { Linguistic scale for } \\
\text { importance }\end{array}$ & $\begin{array}{l}\text { Linguistic scale for } \\
\text { performance }\end{array}$ & $\begin{array}{l}\text { Triangular fuzzy } \\
\text { number }\end{array}$ & $\begin{array}{l}\text { Triangular fuzzy } \\
\text { reciprocal number }\end{array}$ \\
\hline Equally important & Very poor & $(1,1,1)$ & $(1,1,1)$ \\
\hline Weak importance & Poor & $(2,3,4)$ & $(1 / 4,1 / 3,1 / 2)$ \\
\hline Strong importance & Fair & $(4,5,6)$ & $(1 / 6,1 / 5,1 / 4)$ \\
\hline dominant importance & Good & $(6,7,8)$ & $(1 / 8,1 / 7,1 / 6)$ \\
\hline Absolute importance & Very good & $(8,9,10)$ & $(1 / 10,1 / 9,1 / 8)$ \\
\hline
\end{tabular}

\subsection{Fuzzy ANP}

The ANP, developed by Thomas L. Saaty, is an extension of analytic hierarchy process (AHP) (Saaty, 1996). In real world, the elements within the hierarchy of various rules are often interdependent. Steps in the ANP process can be divided as following:

Step 1: the pairwise comparisons.

In the application for performing the pairwise comparisons, triangle fuzzy numbers have been employed by experts to express their preferences as shown in Table 2. The matrix A is clarified as (Kabak el at., 2012):

$$
A=\left[\begin{array}{cccc}
w_{1} / w_{1} & w_{1} / w_{1} & \cdots & w_{1} / w_{1} \\
w_{2} / w_{1} & w_{2} / w_{2} & \cdots & w_{2} / w_{1} \\
\vdots & \vdots & \vdots & \vdots \\
w_{n} / w_{1} & w_{n} / w_{2} & \cdots & w_{n} / w_{n}
\end{array}\right]=\left[\begin{array}{cccc}
1 & a_{21} & \cdots & a_{2 n} \\
1 / a_{12} & 1 & \cdots & 1 / a_{1 n} \\
\vdots & \vdots & \vdots & \vdots \\
1 / a_{1 n} & 1 / a_{2 n} & \cdots & 1
\end{array}\right]
$$

After forming the pairwise comparison matrix $\mathrm{A}$, the weight vector $\mathrm{W}$ can be determined by eigenvector method. The weights from the eigenvector method are calculated by raising the matrix of elements A to increasing powers of $\mathrm{k}$ and then normalizing the resulting system (Brans et al., 1984):

$$
W=\lim _{k \rightarrow \infty} \frac{A^{k} e}{e^{T} A^{k} e},
$$

Step 2: Investigating the consistency of the criteria matrix.

The quality of final pairwise comparison matrices in the ANP process is highly depend on the consistency of judgments that the experts express during the process of pairwise comparisons (Saaty, 1996). After determining the weight of criteria, $\lambda_{\max }$ is calculated shown as:

$$
A W=\lambda_{\max } W,
$$


Where $\lambda_{\max }$ is the largest eigenvalue of matrix A.

Next we investigate the consistency of matrix A, through calculating the inconsistency ratio (CR) of this matrix as it is defined as:

$$
C R=C I / R I,
$$

Where CI stands for inconsistency index and RI stands for inconsistency index of random matrix. Furthermore, CI is calculated by:

$$
C I=\left(\lambda_{\max }-n\right) /(n-1)
$$

If $\mathrm{CR} \leq 0.1$ the pairwise comparison matrix has an acceptable consistency, otherwise, it has to be revised.

Step 3: Aggregate the experts' judgments and construct aggregated fuzzy pairwise comparison matrices.

By considering $\mathrm{K}$ experts (DMs), every pairwise comparison between two elements has $\mathrm{K}$ positive triangular fuzzy numbers. The triangular fuzzy number $\tilde{a}_{i j}=\left(a_{i j 1}, a_{i j}, a_{i j 3}\right), i, j=1,2, \ldots, n$ as the aggregated group of the individual judgment by all $\mathrm{K}$ DMs is calculated using the geometric average approach shown as:

$$
a_{i j 1}=\min \left\{a_{i j 1}^{1}, a_{i j 1}^{2}, \ldots, a_{i j 1}^{k}\right\}, a_{i j}^{2}=\left(\prod_{k=1}^{k} a_{i j 2}^{k}\right)^{1 / k}, a_{i j 3}=\max \left\{a_{i j 3}^{1}, a_{i j 3}^{2}, \ldots, a_{i j 3}^{k}\right\}
$$

Step 4: Construct of the un-weighted super-matrix.

To determine global priorities in a system by considering interdependent influences, the local priority vectors are entered in the appropriate columns of a matrix, known as an un-weighted super-matrix ( Saaty, 1996; Onut et al., 2009).

Step 5: Transform un-weighted super-matrix into weighted super-matrix.

Step 6: Compute the limit super-matrix.

The weighted super-matrix is raised to the power of $2 l+1$ to reach the limit Super-matrix.

Step 7: Obtain the weights of criteria for the fuzzy multi-criteria analysis.

Pairwise comparison are made by employing triangle fuzzy numbers $(l, m, u$ ) ( Onut et al., 2009; Kabak et al., 2012):

$$
A=\left[\begin{array}{cccc}
(1,1,1) & \left(\boldsymbol{a}_{12}^{\prime}, \boldsymbol{a}_{12}^{m}, \boldsymbol{a}_{12}^{u}\right) & \cdots & \left(\boldsymbol{a}_{1 n}^{\prime}, \boldsymbol{a}_{1 n}^{m}, \boldsymbol{a}_{1 n}^{u}\right) \\
\left(\frac{1}{\boldsymbol{a}_{12}^{u}}, \frac{1}{\boldsymbol{a}_{12}^{m}}, \frac{1}{\boldsymbol{a}_{12}^{l}}\right) & (1,1,1) & \cdots & \left(\boldsymbol{a}_{2 n}^{\prime}, \boldsymbol{a}_{2 n}^{m}, \boldsymbol{a}_{2 n}^{u}\right) \\
\vdots & \vdots & \vdots & \vdots \\
\left(\frac{1}{\boldsymbol{a}_{1 n}^{u}}, \frac{1}{\boldsymbol{a}_{1 n}^{m}}, \frac{1}{\boldsymbol{a}_{1 n}^{l}}\right) & \left(\frac{1}{\boldsymbol{a}_{2 n}^{u}}, \frac{1}{\boldsymbol{a}_{2 n}^{m}}, \frac{1}{\boldsymbol{a}_{2 n}^{l}}\right) & \cdots & (1,1,1)
\end{array}\right]
$$


The $a_{m n}$ represents the of comparison $\mathrm{m}$ (row) with component n (column). For calculating triangular fuzzy weights, the logarithmic least squares technique is shown as follows:

$$
W=\left(W_{k}^{l}, W_{k}^{m}, W_{k}^{u}\right)
$$

Where

$$
W_{k}^{p}=\frac{\left(\prod_{j=1}^{n} a_{k j}^{s}\right)^{1 / n}}{\sum_{i=1}^{n}\left(\prod_{j=1}^{n} a_{i j}^{p}\right)^{1 / n}}, \quad p \in\{i, m, u\}
$$

\subsection{Fuzzy TOPSIS}

We apply the TOPSIS method to calculate the overall score for each alternative. According to this method, the alternative with minimum distance from the positive- ideal solution and greatest distance from the negative ideal solution would be best one (Ertugrul and Karakasoglu, 2009). The following characteristics of the TOPSIS method make it an appropriate approach which has good potential for solving selection and evaluation problems (Amiri el at., 2010):

- Employing TOPSIS reduce the number of pair-wise comparisons and can include infinite range of alternative properties and performance attributes.

- In the context of vender selection issues, because the effect of each attribute is not always unilateral and must be considered as a trade-off in term of other attributes, the TOPSIS can be an appropriate method. Many manufacturing managers believe there is trade-off between cost, delivery, flexibility, and service features in the supplier selection issues for raw materials and component parts (Rhee, 2009).

- The output can be determined numerically, a favorable ranking of the vendors, that better show differences and similarities between alternatives, whereas other MADM techniques such as the ELECTRE method only can determine the priority of each vendor.

TOPSIS assumes that there are $m$ alternatives and $n$ attributes (criteria). Given that there are scores of each alternative with respect to each attribute, we can adopt the following procedure for finding the weights.

Let $\tilde{x}_{i j k}=\left(a_{i j k}, b_{i j k}, c_{i j k}\right) ;\{i=1,2,3, \ldots, n, j=1,2,3, \ldots, m\}$

That it is the rating of the $k$ th decision maker for alternative $j$ with respect to criterion $i$. Hence, the aggregated fuzzy ratings $\tilde{x}_{i j k}$ of alternatives with respect to each criterion can be given as following: 


$$
\tilde{x}_{i j}=\left(a_{i j}, b_{i j}, c_{i j}\right) \text { Where } a_{i j}=\min _{k}\left\{a_{i j k}\right\}, \quad b_{i j}=\frac{1}{k} \sum_{k=1}^{K} b_{i j k}, c_{i j}=\max _{k}\left\{c_{i j k}\right\} \text {. }
$$

Output of the ratings will be a matrix $X=\left(\tilde{x}_{i j}\right)$ can be briefly illustrated in following format:

$$
X=\left[\begin{array}{cccc}
\tilde{x}_{11} & \tilde{x}_{12} & \cdots & \tilde{x}_{12} \\
\tilde{x}_{21} & \tilde{x}_{22} & \cdots & \tilde{x}_{32} \\
\vdots & \vdots & \vdots & \vdots \\
\tilde{x}_{j 1} & \tilde{x}_{j 2} & \cdots & \tilde{x}_{j n}
\end{array}\right]
$$

To select the vendor rating by TOPSIS, The following steps can be summarized as follows (Kabak et al., 2012; Onut et al., 2009).

Step 1: Construct normalized decision matrix.

Choose the fuzzy ratings $\left(\tilde{x}_{i j}=\left(a_{i j}, b_{i j}, c_{i j}\right), i=1,2, \ldots, n, j=1,2, \ldots, m\right)$ for alternatives with respect to criteria as formerly stated. Here in a decision process for avoiding complication of mathematical operations, the linear scale transformation is used to convert the various criteria scales into comparable scales. The set of criteria can be divided into benefit criteria and cost criteria. Let $\tilde{x}_{i}^{*}=\left(a_{i}^{*}, b_{i}^{*}, c_{i}^{*}\right)$ and $\tilde{x}_{i}^{-}=\left(a_{i}^{-}, b_{i}^{-}, c_{i}^{-}\right)$; Get $K$ and $K^{\prime}$ are the sets of benefit criteria and cost criteria, respectively, we have:

$$
\begin{aligned}
& \tilde{r}_{i j}=\tilde{x}_{i j} / \tilde{x}_{i}^{*}=\left(\frac{a_{i j}}{a_{i}^{*}}, \frac{b_{i j}}{b_{i}^{*}}, \frac{c_{i j}}{c_{i}^{*}}\right), \quad \text { Where } a_{i}^{*}=\max _{j} a_{i j}, b_{i}^{*}=\max _{j} b_{i j}, a_{i}^{*}=\max _{j} b_{i j}, i \in K, \\
& \tilde{r}_{i j}=\tilde{x}_{i}^{-} / \tilde{x}_{i j}=\left(\frac{a_{i}^{-}}{a_{i j}}, \frac{b_{i}^{-}}{b_{i j}}, \frac{c_{i}^{-}}{c_{i j}}\right), \quad \text { Where } a_{i}^{-}=\min _{j} a_{i j}, b_{i}^{-}=\min _{j} b_{i j}, a_{i}^{-}=\min _{j} b_{i j}, i \in K^{\prime},
\end{aligned}
$$

Step 2: Calculate the weighted normalized decision matrix.

Assume that we have a set of weights for each criterion $\mathrm{w}_{i}$ for $(\mathrm{i}=1,2,3, \ldots, \mathrm{n})$. Where $\mathrm{w}_{i}$ is the weight of the ith criterion. Multiply each column of the normalized decision matrix by its related weight. The new matrix is called $\tilde{v_{i j}}$. Therefore the value of $\tilde{v_{i j}}$ is obtained as following:

$$
\tilde{V_{i j}}=\left[\tilde{v_{i j}}\right]_{n m} \quad\{i=1,2, \ldots, n, j=1,2, \ldots, m\} \text { Where } \tilde{v_{i j}}=\tilde{r_{i j}} \cdot w_{i} \text {. }
$$

Step 3: Determine the positive and negative ideal solutions

As mentioned earlier, positive ideal solutions $\left(\mathrm{A}^{*}\right)$ are near to the best alternative and negative ideal solutions $\left(\mathrm{A}^{-}\right)$are farthest from the alternatives (Hwang and Yoon, 1981). Ideal solution is given by: 


$$
A^{*}=\left\{\tilde{v}_{1}^{*}, \tilde{v}_{2}^{*}, \ldots, \tilde{v}_{i}^{*}\right\} \text {, Where } \tilde{v_{i}}=\left\{\left(\max _{j} v_{i j} \mathrm{I} i \in K\right),\left(\min _{j} v_{i j} \mathrm{I} i \in K^{\prime}\right)\right\}
$$

Similarly negative ideal solution is given by,

$$
A^{-}=\left\{\tilde{v_{1}^{-}}, \tilde{v_{2}^{-}} \ldots, \tilde{v_{i}^{-}}\right\} \text {, Where } \tilde{v_{i}}=\left\{\left(\min _{j} v_{i j} \mathrm{I} i \in K\right),\left(\max _{j} v_{i j} \mathrm{I} i \in K^{\prime}\right)\right\}
$$

Step 4: Calculate the distance of each alternative from $\mathrm{A}^{*}$ and $\mathrm{A}^{-}$.

Let $\tilde{a}=\left(a_{1}, a_{2}, a_{3}\right)$ and $\tilde{b}=\left(b_{1}, b_{2}, b_{3}\right)$ be two triangular fuzzy numbers. afterward, the distance between them is determined by employing the vertex technique (Chen, 2000).

$$
d(\tilde{a}, \tilde{b})=\sqrt{\left.\frac{1}{3}\left[\left(a_{1}-b_{1}\right)^{2}+\left(a_{2}-b_{2}\right)^{2}+\left(a_{3}-b_{3}\right)^{2}\right)\right]}
$$

By the formula, the two distances for each alternative are respectively calculated as:

$$
\begin{aligned}
& D_{j}^{*}=\sum_{i=1}^{n} d\left(\tilde{v}_{i j}, v_{i}^{*}\right)\{j=1,2,3, \ldots, m\}, \\
& D_{j}^{-}=\sum_{i=1}^{n} d\left(\tilde{v}_{i j}, v_{i}^{-}\right)\{j=1,2,3, \ldots, m\},
\end{aligned}
$$

Step 5: Calculate the relative closeness to the ideal solution.

A closeness coefficient is defined to determine the ranking order of all possible alternatives by using $D_{j}^{*}$ and $D_{j}^{-}$of each alternative. The closeness coefficient $\left(C C_{j}\right)$ of each alternative can be defined as:

$$
C C_{j}=\frac{D_{j}^{-}}{D_{j}^{-}+D_{j}^{*}},\{j=1,2,3, \ldots, m\}
$$

Thus the best alternative can be selected with $C C_{i}$ closest to 1 . In other words, the higher the closeness means the better the rank. Therefore, the best alternative can be selected from among a set of possible alternatives.

\section{The integrated model to the vendor selection}

The proposed model for the vendor selection problem, combined of fuzzy ANP and fuzzy TOPSIS, include three basic phase: (1) identifying the criteria and vendors to be applied in the model and determining the network relationships among criteria (2) using fuzzy ANP for computing sub-criteria weight and (3) determining of the final rank of vendors with fuzzy TOPSIS. Diagrammatic diagram of the proposed model for vendor selection issue is shown in Figure 1. 


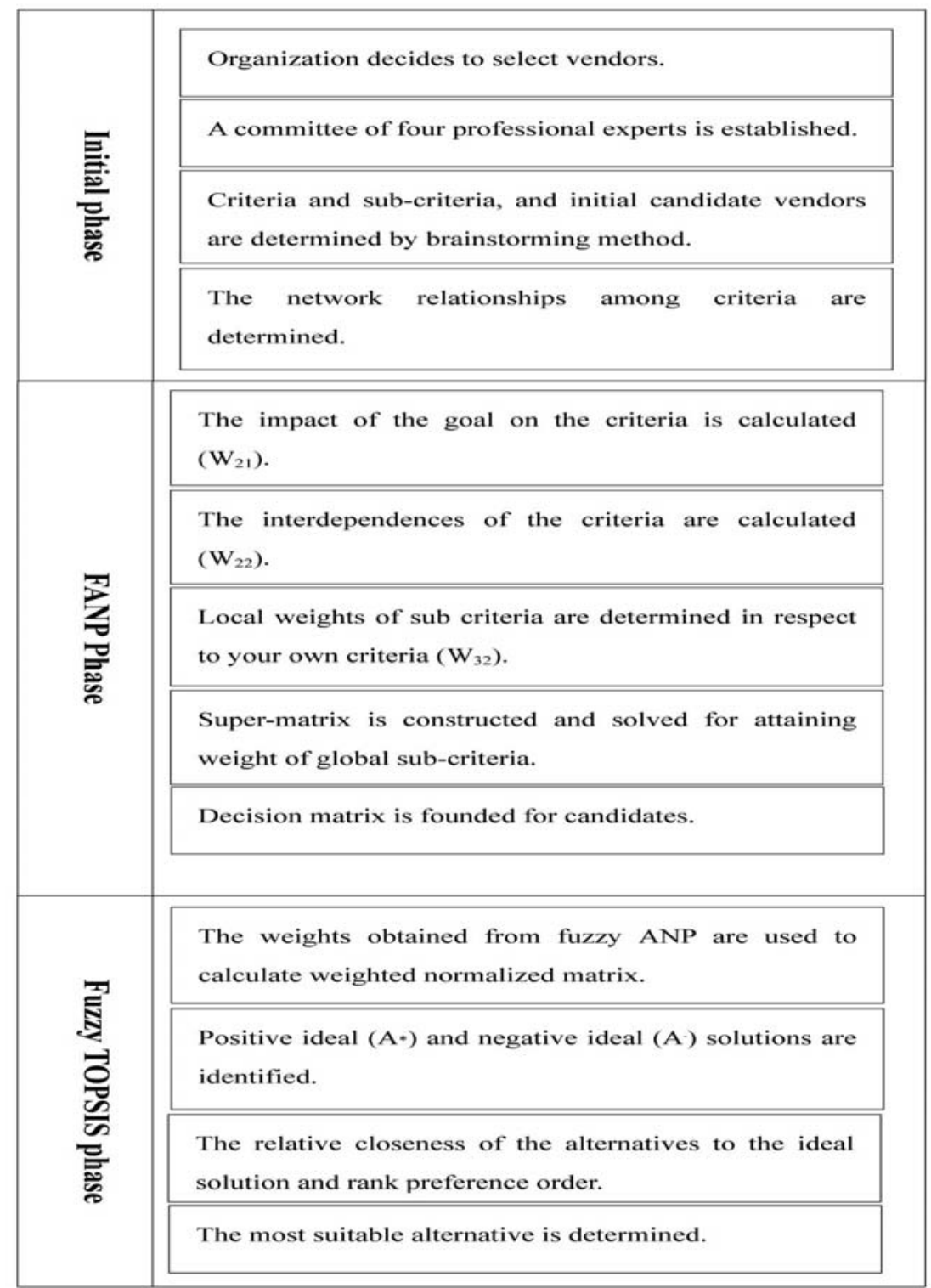

Figure 1. The phases of proposed model

The purpose of the empirical application is to illustrate the use of the proposed model. For this aim, in this section a vender selection project in Iran Khodro Company is described to illustrate the details of the proposed approach and demonstrate how it can be employed in practice. The Iran Khodro (IK) company is one that produce automobile, particularly receives parts and material from its vendors and assembles them. Most parts component and raw material of the IK is outsourced in house. Therefore, in outsourcing the requirements, it is critical to evaluate and select sources and vendors that can improve position of the company. In other hand, procurement system recently has faced the problem of venders' wrong selection. Selection of a wrong vendor or supplier could upset the company's position in its competitive environment. Due to the facts, for selecting competent vendor, various criteria must be considered and the criteria are usually interdependent on each other in the decision making process. For the purpose, a committee of five professional experts $\left(E_{1}, E_{2}, E_{3}, E_{4}\right)$ is 


\section{Macrothink}

Business and Management Horizons

ISSN 2326-0297

2013, Vol. 1, No. 1

established including managers from different functional divisions of the case company (i.e., purchasing director, quality manager, product designing director and production manager). Therefore, members of the team comprised the different experts bringing particular concerns and desire into the evaluation.

The criteria involved in the vendor selection have been chosen according to the experts' professional knowledge and experiences. Here, to find out the central criteria for improving the performance of an appropriate and best vendor in the complex system, an effective criteria selection model based on the brainstorming method is needed. These major criteria involved in vendor selection are provided in Table 2.

Table 2. Criteria and sub-criteria for the vendor selection

\begin{tabular}{|l|l|}
\hline Quality (Q) & \\
\hline (PQ) & Product quality \\
\hline (SS) & Service satisfaction \\
\hline Price \& deliver condition (P \& DC) & \\
\hline (PP) & Product price \\
\hline (R) & Responsiveness \\
\hline (DO) & Delivery operation \\
\hline (DT) & Delivery time \\
\hline Supply chain support (SCS) & \\
\hline (POR) & Purchase order reactiveness \\
\hline (CSF) & Capacity support \& flexibility \\
\hline Technology (T) & \\
\hline (TS) & Technical support \\
\hline (DI) & Design involvement \\
\hline
\end{tabular}

Also, the committee chooses four vendors $\left(V_{1}, V_{2}, V_{3}\right.$ and $\left.V_{4}\right)$ as initial candidate based the screening processes. These venders are eligible for selection. Then, the committee determines the network relationships and weights among criteria. The expert also gives the performance rating for each candidate vendor in terms of all sub-criteria in the evaluation process. As before stated, in first phase we should determine the network relationships among criteria influencing on each other. The network relationship between the criteria according to the group decision is stated in Figure 2. 


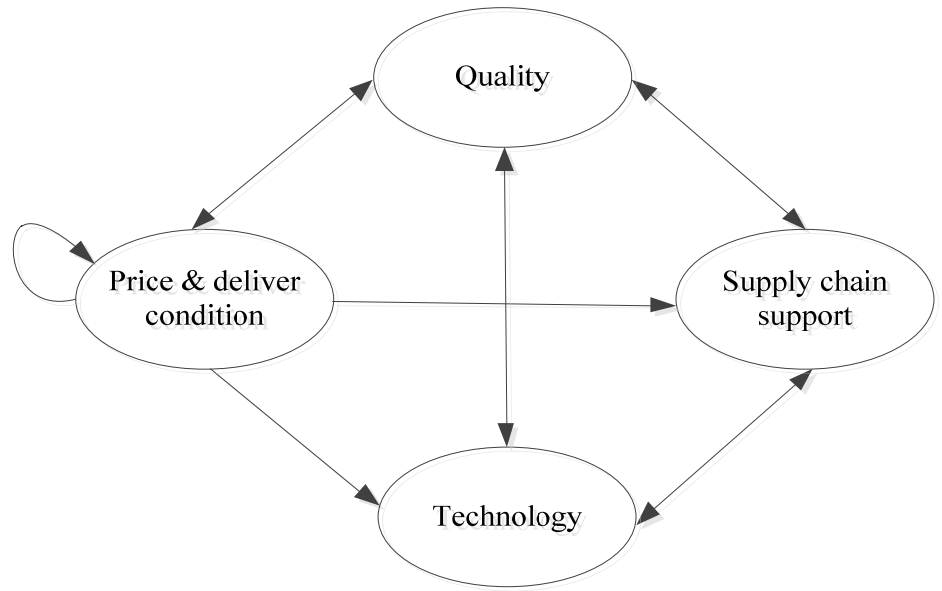

Figure 2. Network relationship map of impacts for the vendor selection problem

Table 3 summarizes the pair-wise comparison of the four criteria with respect to the overall goal and the four criteria $\left(\mathrm{W}_{21}, \mathrm{~W}_{22}\right)$.

Table 3. Aggregated fuzzy pair wise comparison matrix of the four criteria with respect to the overall goal and the four criteria (inner dependence)

\begin{tabular}{|c|c|c|c|c|c|}
\hline & Q & P \& DC & SCS & $\mathrm{T}$ & $\begin{array}{l}\text { Crisp } \\
\text { weights }\end{array}$ \\
\hline \multicolumn{6}{|c|}{ With respect to sustainable vendor selection (Goal) } \\
\hline $\mathrm{Q}$ & $(1,1,1)$ & $(0.17,0.29,0.5)$ & $(4,6.3,10)$ & $(2,4.21,8)$ & 0.29 \\
\hline P \& DC & $(2,3.4,6)$ & $(1,1,1)$ & $(6,7.94,10)$ & $(2,5.66,8)$ & 0.57 \\
\hline SCS & $(0.1,0.16,0.25)$ & $(0.1,0.13,0.17)$ & $(1,1,1)$ & $(0.25,0.33,0.5)$ & 0.05 \\
\hline $\mathrm{T}$ & $(0.12,0.24,0.5)$ & $(0.12,0.18,0.5)$ & $(2,3,4)$ & $(1,1,1)$ & 0.11 \\
\hline \multicolumn{6}{|c|}{ With respect to quality (Q) } \\
\hline P \& DC & & $(1,1,1)$ & $(4,6.85,10)$ & $(2,5.66,8)$ & 0.71 \\
\hline SCS & & $(0.1,0.15,0.25)$ & $(1,1,1)$ & $(2,3.41,6)$ & 0.18 \\
\hline $\mathrm{T}$ & & $(0.12,0.18,0.5)$ & $(0.17,0.29,0.5)$ & $(1,1,1)$ & 0.09 \\
\hline \multicolumn{6}{|c|}{ With respect to price \& deliver condition (P \& DC) } \\
\hline $\mathrm{Q}$ & $(1,1,1)$ & $(0.12,0.27,0.5)$ & $(4,6.3,10)$ & $(6,7.94,10)$ & 0.30 \\
\hline P \& DC & $(2,3.7,8)$ & $(1,1,1)$ & $(4,6.43,8)$ & $(6,8.45,10)$ & 0.59 \\
\hline SCS & $(0.1,0.16,0.25)$ & $(0.12,0.16,0.25)$ & $(1,1,1)$ & $(2,3.87,6)$ & 0.09 \\
\hline $\mathrm{T}$ & $(0.1,0.13,0.17)$ & $(0.1,0.12,0.17)$ & $(0.17,0.26,0.5)$ & $(1,1,1)$ & 0.04 \\
\hline \multicolumn{6}{|c|}{ With respect to supply chain support (SCS) } \\
\hline $\mathrm{Q}$ & $(1,1,1)$ & & & $(4,5.44,8)$ & 0.87 \\
\hline P \& DC & $(0.12,0.18,0.25)$ & & & $(1,1,1)$ & 0.15 \\
\hline \multicolumn{6}{|c|}{ With respect to technology $(\mathrm{T})$} \\
\hline $\mathrm{Q}$ & $(1,1,1)$ & & $(4,6.3,10)$ & & 0.88 \\
\hline SCS & $(0.1,0.16,0.25)$ & & $(1,1,1)$ & & 0.14 \\
\hline
\end{tabular}


Then, local weights of the sub-criteria $\left(\mathrm{W}_{32}\right)$ were determined by using the pairwise comparison matrices listed in Table 4-7.

Table 4. Aggregated local weights of 4 sub criteria of the Q

\begin{tabular}{|l|l|l|l|}
\hline & PQ & SS & Crisp weights \\
\hline PQ & $(1,1,1)$ & $(1,2.6,6)$ & 0.76 \\
\hline SS & $(0.17,0.38,1)$ & $(1,1,1)$ & 0.30 \\
\hline
\end{tabular}

Table 5. Aggregated local weights of 4 sub criteria of the P \& DC

\begin{tabular}{|l|l|l|l|l|l|}
\hline & PP & R & DO & DT & $\begin{array}{l}\text { Crisp } \\
\text { weights }\end{array}$ \\
\hline PP & $(1,1,1)$ & $(1,2.6,6)$ & $(2,4.21,10)$ & $(2,4.79,10)$ & 0.59 \\
\hline R & $(0.17,0.38,1)$ & $(1,1,1)$ & $(1,2.6,6)$ & $(2,3.7,8)$ & 0.31 \\
\hline DO & $(0.1,0.24,0.5)$ & $(0.17,0.38,1)$ & $(1,1,1)$ & $(1,2.6,6)$ & 0.15 \\
\hline DT & $(0.1,0.21,0.5)$ & $(0.12,0.27,0.5)$ & $(0.17,0.38,1)$ & $(1,1,1)$ & 0.06 \\
\hline
\end{tabular}

Table 6. Aggregated local weights of 4 sub criteria of the SCS

\begin{tabular}{|l|l|l|l|}
\hline & POR & CSF & Crisp weights \\
\hline POR & $(1,1,1)$ & $(1,2.14,8)$ & 0.82 \\
\hline CSF & $(0.12,0.47,1)$ & $(1,1,1)$ & 0.32 \\
\hline
\end{tabular}

Table 7. Aggregated local 1 weights of 4 sub criteria of the $\mathrm{T}$

\begin{tabular}{|l|l|l|l|}
\hline & TS & DI & Crisp weights \\
\hline TS & $(1,1,1)$ & $(2,3.87,6)$ & 0.78 \\
\hline DI & $(0.17,0.26,0.5)$ & $(1,1,1)$ & 0.22 \\
\hline
\end{tabular}

The third phase of the paper, arrange fuzzy evaluations of the vendors $\left(A_{1}, A_{2}, A_{3} ., A_{4}\right)$ as shown in table 1 . Product of the evaluations is a decision matrix indicating the performance ratings of the alternatives in term of to the sub-criteria as shown in Table 8. After forming the decision matrix, a normalized weighted decision matrix is calculated by using the sub-criteria weights derived from fuzzy ANP. This matrix is shown in Table 9. 


\section{Al Macrothink}

Business and Management Horizons

Table 8. Aggregated decision matrix for performance evaluation of 4 vendors

\begin{tabular}{|l|l|l|l|l|}
\hline & $\mathrm{A}_{1}$ & $\mathrm{~A}_{2}$ & $\mathrm{~A}_{3}$ & $\mathrm{~A}_{4}$ \\
\hline$(\mathrm{PQ})$ & $(1,1.31,4)$ & $(4,6.3,10)$ & $(2,5.1,10)$ & $(2,2.6,6)$ \\
\hline$(\mathrm{SS})$ & $(1,2.82,8)$ & $(2,4.03,8)$ & $(2,4.03,8)$ & $(1,1.97,6)$ \\
\hline$(\mathrm{PP})$ & $(2,4.22,8)$ & $(1,2.6,6)$ & $(4,6.3,10)$ & $(2,4.49,10)$ \\
\hline$(\mathrm{R})$ & $(1,1.97,6)$ & $(2,5.54,10)$ & $(1,1.73,4)$ & $(1,2.6,6)$ \\
\hline$(\mathrm{DO})$ & $(1,2.81,8)$ & $(4,7.3,10)$ & $(1,2.6,6)$ & $(2,5.54,10)$ \\
\hline$(\mathrm{DT})$ & $(6,7.94,10)$ & $(1,2.81,8)$ & $(4,6.85,10)$ & $(1,1.31,4)$ \\
\hline$(\mathrm{POR})$ & $(2,4.4,6)$ & $(4,6.3,10)$ & $(2,4.22,8)$ & $(1,2.6,6)$ \\
\hline$(\mathrm{CSF})$ & $(1,3.64,8)$ & $(2,5.1,10)$ & $(4,5.91,8)$ & $(1,1.73,4)$ \\
\hline$(\mathrm{TS})$ & $(2,5.54,10)$ & $(2,4.22,8)$ & $(4,6.85,10)$ & $(1,1.96,6)$ \\
\hline$(\mathrm{DI})$ & $(4,6.3,10)$ & $(1,1.73,4)$ & $(2,4.58,8)$ & $(2,4.03,8)$ \\
\hline
\end{tabular}

Table 9. The weighted normalized decision matrix

\begin{tabular}{|l|l|l|l|l|l|}
\hline & Weight & $\mathrm{A}_{1}$ & $\mathrm{~A}_{2}$ & $\mathrm{~A}_{3}$ & $\mathrm{~A}_{4}$ \\
\hline$(\mathrm{PQ})$ & 0.175 & $(0.052,0.043,0.082)$ & $(0.206,0.206,0.206)$ & $(0.103,0.167,0.206)$ & $(0.103,0.085,0.124)$, \\
\hline (SS) & 0.061 & $(0.042,0.058,0.083)$ & $(0.083,0.083,0.083)$ & $(0.083,0.083,0.083)$ & $(0.042,0.041,0.062)$ \\
\hline$(\mathrm{PP})$ & 0.281 & $(0.143,0.176,0.215)$ & $(0.286,0.286,0.286)$ & $(0.072,0.118,0.172)$ & $(0.143,0.166,0.172)$ \\
\hline$(\mathrm{R})$ & 0.128 & $(0.076,0.054,0.091)$ & $(0.151,0.151,0.151)$ & $(0.076,0.047,0.060)$ & $(0.076,0.071,0.091)$ \\
\hline (DO) & 0.065 & $(0.019,0.029,0.060)$ & $(0.075,0.075,0.075)$ & $(0.019,0.027,0.045)$ & $(0.038,0.057,0.075)$ \\
\hline (DT) & 0.039 & $(0.005,0.004,0.012)$ & $(0.031,0.012,0.016)$ & $(0.008,0.005,0.012)$ & $(0.031,0.031,0.031)$ \\
\hline (POR) & 0.137 & $(0.033,0.046,0.040)$ & $(0.066,0.066,0.066)$ & $(0.033,0.044,0.053)$ & $(0017,0.027,0.040)$ \\
\hline (CSF) & 0.048 & $(0.006,0.015,0.020)$ & $(0.013,0.022,0.025)$ & $(0.025,0.025,0.020)$ & $(0.006,0.007,0.010)$ \\
\hline (TS) & 0.05 & $0.030,0.049,0.060)$ & $(0.030,0.037,0.048)$ & $(0.060,0.060,0.060)$ & $(0.015,0.017,0.036)$ \\
\hline (DI) & 0.017 & $(0.017,0.017,0.017)$ & $(0.004,0.005 .0 .007)$ & $(0.009,0.012,0.014)$ & $0.009,0.011,0.014)$ \\
\hline
\end{tabular}

Moreover the fuzzy positive ideal solution $\left(\mathrm{A}^{*}\right)$ and the fuzzy negative ideal solution $\left(\mathrm{A}^{-}\right)$ are calculated using Eqs. (13) and (14). The distance of each alternative from $\mathrm{A}^{*}$ and $\mathrm{A}^{-}$is computed by using Eqs. (21) and (22). In the end, closeness to the ideal solution are calculated and ranked in preference orders using Eq. (23). An alternative with maximum $\mathrm{Cl}_{\mathrm{j}}$ is chosen or alternatives according to $\mathrm{Cl}_{\mathrm{j}}$ are ranked in descending order. According to the Fuzzy TOPSIS, the best alternative for the vendor selection problem is determined as $A_{2}$. The alternatives are ranked as $A_{2}, A_{1}, A_{4}$ and $A_{5}$, respectively, shown in Table 10. 
Table 10. Computations of overall scores of the 4 vendors and their priority ranking

\begin{tabular}{|l|l|l|l|l|}
\hline & $\mathrm{d}_{\mathrm{j}}^{+}$ & $\mathrm{d}_{\mathrm{j}}^{-}$ & $\mathrm{Cl}_{\mathrm{j}}$ & $\begin{array}{l}\text { Priority } \\
\text { ranking }\end{array}$ \\
\hline $\mathrm{A}_{1}$ & 0.492 & 0.479 & 0.49 & 2 \\
\hline $\mathrm{A}_{2}$ & 0.056 & 0.558 & 0.91 & 1 \\
\hline $\mathrm{A}_{3}$ & 0.427 & 0.362 & 0.46 & 4 \\
\hline $\mathrm{A}_{4}$ & 0.464 & 0.321 & 0.41 & 3 \\
\hline
\end{tabular}

\section{Conclusion}

In this paper, we have proposed a new integrated hybrid MCDM model to evaluate for solving vendor selection issue. The proposed hybrid MCDM model has used Fuzzy ANP and Fuzzy TOPSIS to determine the weights of sub-criteria and attain ranking of the vendors. Due to the fact that criteria of our issue are interdependent on each other in practice, we introduced the fuzzy analytic network process (ANP) for obtaining a set of suitable weights of the sub-criteria. Also the fuzzy TOPSIS is employed to rank competing vendors in terms of their overall performance with multiple sub-criteria. Important feature of the technique is to allows explicit trade-offs and interactions among attributes. Various different kinds of MCDM methods can be employed in future studies regarding vendor selection issue. As a future work to this paper could be the comparison of the proposed approach to other MCDM methods, like VIKOR, ELECTRE and even AHP.

\section{Acknowledgements}

The authors would like to thank the anonymous reviewers and the editor for their insightful comments and suggestions.

\section{References}

Amiri, M., Zandieh, M., Vahdani, B., Soltani, R., \& Roshanaei, V. (2010). An integrated eigenvector-DEA-TOPSIS methodology for portfolio risk evaluation in the FOREX spot market. Expert Systems with Applications, 37, 509-516. http://dx.doi.org/10.1016/j.eswa.2009.05.041

Brans, J. P., Vinke, P. H., \& Mareschal, B. (1984). PROMETHEE: A new family of outranking methods in multicriteria analysis. In J. P. Brans (Ed.), Operations research '84 (pp. 477-490). Elsevier Science Publishers.

Carney, D. J., \& Wallnau, K. C. (1998). A basis for evaluation of commercial software. Information and Software Technology, 40, 851-860. http://dx.doi.org/10.1016/S0950-5849(98)00099-8

Chen, C. T. (2000). Extensions of the TOPSIS for group decision-making under fuzzy $\begin{array}{llllll}\text { environment. Fuzzy } & \text { Sets } & \text { Systems, } & 114, & 1-9 .\end{array}$ http://dx.doi.org/10.1016/S0165-0114(97)00377-1 
De Boer, L., Labro, E., \& Morlacchi, P. (2001). A review of methods supporting supplier selection. European Journal of Purchasing and Supply Management, 7(2), 75-89. http://dx.doi.org/10.1016/S0969-7012(00)00028-9

Ding, J. F., \& Liang, G. S. (2005). Using fuzzy MCDM to select partners of strategic alliances for liner shipping. Information Sciences, 173(1-3), 197-225. http://dx.doi.org/10.1016/j.ins.2004.07.013

Erol, I., William, G., \& Ferrell Jr., W. G. (2003). A methodology for selection problems with multiple, conflicting objectives and both qualitative and quantitative criteria. International $\begin{array}{lllr}\text { Journal of } & \text { Production } & \text { Economics, } & \text { 86, }\end{array}$ http://dx.doi.org/10.1016/S0925-5273(03)00049-5

Ertugrul, I., \& Karakasoglu, N. (2009). Performance evaluation of Turkish cement firms with fuzzy analytic hierarchy process and TOPSIS methods. Expert Systems with Applications, 36, 702-715. http://dx.doi.org/10.1016/j.eswa.2007.10.014

Faeza, F., Ghodsypoura, S. H, \& O’Brien, C. (2009). Vendor selection and order allocation using an integrated fuzzy case-based reasoning and mathematical programming model. International Journal of Production Economics, 121, 395-408. http://dx.doi.org/10.1016/j.ijpe.2006.11.022

Ghodsypour, S. H., \& O’Brien, C. (1998). A decision support system for supplier selection using an integrated analytic hierarchy process and linear programming. International Journal of Production Economics, 56-57, 199-212. http://dx.doi.org/10.1016/S0925-5273(97)00009-1

Hwang, C. L., \& Yoon, K. (1981). Multiple attribute decision making-methods and applications: A state of the art survey. Springer-Verlag.

Kabak, M., Serhat, B., \& Yigit, K. (2012). A fuzzy hybrid MCDM approach for professional selection. Expert Systems with Applications, 39, 3516-3525. http://dx.doi.org/10.1016/j.eswa.2011.09.042

Karsak, E. E., \& Tolga, E. (2001). Fuzzy multi-criteria decision-making procedure for evaluating advanced manufacturing system investments. International Journal of Production Economics, 69(1), 49-64. http://dx.doi.org/10.1016/S0925-5273(00)00081-5

Kumar, M., Vrat, P., \& Shankar, R. (2004). A fuzzy goal programming approach for vendor selection problem in a supply chain. Computers \& Industrial Engineering, 46, 69-85. http://dx.doi.org/10.1016/j.cie.2003.09.010

Lin, Y. T., Lin, C. L., Yu, H. C., \& Tzeng, G. H. (2010). A novel hybrid MCDM approach for outsourcing vendor selection: A case study for a semiconductor company in Taiwan. Expert Systems with Applications, 37, 4796-4804. http://dx.doi.org/10.1016/j.eswa.2009.12.036

Meade, L. M., \& Sarkis, J. (1999). Analyzing organizational project alternatives for agile manufacturing processes: An analytical network approach. International Journal of Production Research, 37(2), 241-261. 
Narasimhan, R. (1983). An analytic approach to supplier selection. Journal of Purchasing and Materials Management Winter, 27-32. http://dx.doi.org/10.1108/09576050310503376

Onut, S., Kara, S. S., \& Isık, E. (2009). Long term supplier selection using a combined fuzzy MCDM approach: A case study for a telecommunication company. Expert Systems with Applications, 36, 3887-3895. http://dx.doi.org/10.1016/j.eswa.2008.02.045

Rhee, V. D. R., Verma, V., \& Plaschka, G. (2009). Understanding trade-offs in the supplier selection process: The role of flexibility, delivery, and value-added services/support. International Journal of Production Economics, 120, 30-41. http://dx.doi.org/10.1016/j.ijpe.2008.07.024

Saaty, T. L. (1996). Decision making with dependence and feedback: The analytic network process. Pittsburgh: RWS Publications Publishers.

Shyur, H. J., \& Shih, H. S. (2006). A hybrid MCDM model for strategic vendor selection, $\begin{array}{llll}\text { Mathematical and Computer Modelling, 44(8), } & \text { 749-761. }\end{array}$ http://dx.doi.org/10.1016/j.mcm.2005.04.018

Tam, M. C. Y., \& Tummala, V. M. R. (2001). An application of the AHP in vendor selection of a telecommunications system. Omega, 29, 171-182. http://dx.doi.org/10.1016/S0305-0483(00)00039-6

Wadhwa, V., \& Ravindran, A. R. (2007). Vendor selection in outsourcing. Computers and Operations Research, 34, 3725-3737. http://dx.doi.org/10.1016/j.cor.2006.01.009

Wu, W. W., \& Lee, Y. T. (2007). Developing global managers' competencies using the fuzzy DEMATEL method. Expert Systems with Applications, 32(2), 499-507. http://dx.doi.org/10.1016/j.eswa.2005.12.005

Yager, R. R. (1981). A procedure for ordering fuzzy subsets of the unit interval. Information Sciences, 24, 143-161.

Yang, J. L., Chiu, H. N., \& Tzeng, G. H. (2008). Vendor selection by integrated fuzzy MCDM techniques with independence and interdependence. Information Sciences, 178(21), 4166-4183. http://dx.doi.org/10.1016/j.ins.2008.06.003

Zadeh, L. A. (1965). Fuzzy sets. Information and Control, 8(3), 338-353.

Zadeh, L. A. (1975). The concept of a linguistic variable and its application to approximate reasoning-I. Information $\quad$ Sciences, $\quad 8(3), \quad 199-249$. http://dx.doi.org/10.1016/0020-0255(75)90036-5

\section{Copyright Disclaimer}

Copyright reserved by the author(s).

This article is an open-access article distributed under the terms and conditions of the Creative Commons Attribution license (http://creativecommons.org/licenses/by/3.0/). 